\title{
ENSINO HÍBRIDO E EDUCAÇÃO AMBIENTAL: Uma Intersecção Possível
}

\author{
Suelen de Gaspi ${ }^{1}$ \\ Carlos Alberto de Oliveira Magalhães Júnior²
}

\begin{abstract}
RESUMO
Esta pesquisa apresenta contribuições teórico-metodológicas para o ensino de Educação Ambiental (EA) na perspectiva do Ensino Híbrido. O objetivo deste estudo foi investigar se a organização da atividade didática, no modelo de Ensino Híbrido, proporciona condições adequadas para o despertar de um sujeito ecológico pautado na Educação Ambiental Crítica. Os dados da pesquisa foram organizados e interpretados por meio da Análise de Conteúdo e evidenciam que as ações de EA contribuem para a formação de uma nova perspectiva dos estudantes em relação ao meio ambiente, denotando um desejo de mudança e transformação ambiental, no entanto destaca-se a necessidade de ampliação do discurso de EA que considere as questões sociais. $O$ estudo contribui com a afirmação de que as tecnologias são aliadas ao processo de ensino, dinamizando a aprendizagem e culminando em ações de autonomia e criticidade por parte dos alunos.
\end{abstract}

Palavras-chave: Tecnologias digitais. Processo pedagógico. Meio ambiente.

\section{BLENDED LEARNING AND ENVIRONMENTAL EDUCATION: A POSSIBLE INTERSECTION}

\begin{abstract}
This research presents theoretical-methodological contributions to the teaching of Environmental Education (EE) from the perspective of Blended Learning. The objective of this study was to investigate whether the organization of didactic activity, in the Blended Learning model, provides adequate conditions for the awakening of an ecological subject based on Critical Environmental Education. The research data were organized and interpreted through the Content Analysis and showed that the actions of EE made it possible to conduct a new perspective of the students in relation to the environment, denoting a desire for change and environmental transformation, however, it highlighted the need to broaden the EE discourse that considers social issues; also showed that technologies were allied in the teaching process, stimulating learning and culminating in actions of autonomy and criticality on the part of students.
\end{abstract}

Keywords: Digital technologies. Pedagogical process. Environment.

RECEBIDO EM: 17/7/2019

ACEITO EM: 4/9/2019

\footnotetext{
${ }^{1}$ Doutoranda em Educação para a Ciência e a Matemática (UEM). Mestrado em Ensino de Ciências Ambientais (UEM). Graduação em Licenciatura Plena em Matemática (2010) e em Ciências Econômicas pela Faculdade Estadual de Ciências e Letras de Campo Mourão (2007). Servidora do Instituto Federal do Paraná como assistente em Administração. Linhas de pesquisa: Representações Sociais, Educação Ambiental e Tecnologias na Educação. http://lattes.cnpq.br/2287625921248280. https://orcid.org/0000-0002-4564-7209. suelen.gaspi@ ifpr.edu.br

${ }^{2}$ Licenciado em Ciências pela Universidade Estadual de Maringá (2002). Especialista em Educação pela Universidade Estadual do Paraná (Unespar - Campo Mourão/PR, 2004). Mestrado em Ensino de Ciências (Modalidade Física) pela Universidade de São Paulo (USP, 2007). Doutorado em Ciências pela Universidade Estadual de Maringá (UEM, 2011). Pós-Doutorado em Educação em Ciências pela Universidade do Minho (UMinho/PT, 2016) e em Educação pela Universidade Federal Fluminense (2018). Professor-associado do Departamento de Ciências, do Programa de Pós-Graduação em Educação para a Ciência e a Matemática (PCM) e do Programa de Pós-Graduação Mestrado em Rede Nacional para o Ensino das Ciências Ambientais (PROFCIAMB - UEM). Coordena o Grupo de Pesquisa em Ensino de Ciências, Formação de Professores e Representações Sociais (Cienciar), membro do Grupo de Pesquisa Getepec (UEL) e parceria em pesquisa com o Ciec (Instituto de Educação da UMinho de Portugal). Coordenador do Programa de Pós-Graduação PCM e do Projeto de Pesquisa Interinstitucional entre UEM, Unijuí e UMinho/PT (MCTI/CNPq/Universal 14/2014). Tem experiência na área de Educação, com ênfase em Ensino de Ciências, atuando principalmente nos seguintes temas: formação de professores e representações sociais. http://lattes.cnpq. br/3766552181829432.https://orcid.org/0000-0002-1116-0777.juniormagalhaes@hotmail.com
} 
O século 21 apresenta uma sociedade que vivencia uma era marcada por transformações de cunho cultural e tecnológico, pela informatização técnico-científica, pela globalização e pela exploração e distribuição dos recursos (GOMES, 2014). Nesse cenário, marcado por transformações, evidencia-se a reflexão de que os problemas ambientais ameaçam o futuro do planeta e, ainda, "apontam para a necessidade de uma profunda reorientação nos modos socialmente construídos de conhecer e de se relacionar com a natureza" (CARVALHO, 1998, p. 17). A EA emerge com o objetivo de despertar o debate das relações entre a sociedade e a forma como esta usufrui dos recursos naturais, a fim de construir uma nova concepção de racionalidade ecossistêmica (LEFF, 2001).

Os Parâmetros Curriculares Nacionais - PCNs - (BRASIL, 1998) regulamentam que a educação do século 21 deve estar pautada em quatro pilares: aprender a conhecer; aprender a fazer; aprender a viver com os outros; e aprender a ser; pilares estes que, alicerçados pelas concepções educacionais modernas, impõem uma nova forma de pensar a educação, tendo em vista que a humanidade atingiu um momento que exige uma sensibilização capaz de traçar novos caminhos e refletir sobre a cultura, as crenças, os valores e os conhecimentos, em que "[...] se baseia o comportamento cotidiano, assim como sobre o paradigma antropológico social que persiste nas ações no qual a educação tem um enorme peso" (LUZZI, 2014, p. 445).

A educação contemporânea tem sido invocada como a salvação de problemas com os quais nos deparamos frequentemente. Dentre eles, podemos destacar as crises associadas ao mundo do trabalho, ao meio ambiente, ao desenvolvimento social, às dimensões éticas, etc. (LIMA, 2013). Apesar, no entanto, da importância destes temas no contexto escolar, nossos olhares, nesta pesquisa, voltam-se à reflexão sobre o meio ambiente, tendo em vista que o momento atual nos remete a uma crise ambiental desafiadora para a sociedade contemporânea (LOUREIRO, 2000).

Essa preocupação é endossada pela regulamentação da Lei 9.795/99, que estabelece que a EA seja trabalhada de maneira "[...] essencial e permanente da educação nacional, devendo estar presente, de forma articulada, em todos os níveis e modalidades do processo educativo, em caráter formal e não-formal” (BRASIL, 1999, artigo 2o). Tal regulamentação também se apresenta nos PCNs, destacando a importância de que os estudantes sejam levados a refletir sobre questões que afetam seu contexto social e possibilitem uma sensibilização crítica na qual se relacionem os conteúdos curriculares e a realidade experienciada (BRASIL, 1997).

Para o documento, a principal função do trabalho com o tema Meio Ambiente no espaço escolar "é contribuir para a formação de cidadãos conscientes, aptos a decidir e atuar na realidade socioambiental de um modo comprometido com a vida, com o bem-estar de cada um e da sociedade, local e global (BRASIL, 1997, p. 187). Pressupõe, ainda, que os alunos possam identificar os elementos que forneçam bem-estar à sociedade; auxiliando-os a desenvolver um olhar crítico relativo ao consumo exagerado e ao senso de responsabilidade no uso dos recursos naturais, respeitando o ambiente e as pessoas em sua comunidade (BRASIL, 1997). 
Essa percepção será possível por meio de uma educação crítica que possibilite aos estudantes a ampliação de conhecimentos que contemple inter-relações, tanto com os pares quanto com o meio natural e social, por intermédio de metodologias e práticas pedagógicas ativas, e que vão ao encontro dos anseios da sociedade.

Saviani (2007, p. 48) argumenta que, se considerando que a educação visa à ascensão do homem, são as necessidades humanas que determinarão os objetivos educacionais. Diante de um cenário social marcado pelo advento das tecnologias digitais de informação e comunicação (TDICs), a escola precisa adaptar-se para esta nova realidade.

Kenski (2012) atribui um duplo papel à educação. O primeiro refere-se a se adaptar aos avanços oriundos das tecnologias; o segundo, a se orientar para uma assimilação crítica desses novos meios. $O$ ensino de hoje deve pautar-se na evolução de habilidades que estimulem o desenvolvimento da cidadania e o pensamento crítico dos estudantes.

Valente, Almeida e Geraldini (2017) salientam que um dos desafios da educação contemporânea é repensar propostas educativas inovadoras que possam superar a instrução convencional, imbricada no livro didático e centrada no professor. De acordo com os autores,

[...] é importante considerar as práticas sociais inerentes à cultura digital, marcadas pela participação, criação, invenção, abertura dos limites espaciais e temporais da sala de aula e dos espaços formais de educação, integrando distintos espaços de produção do saber, contextos e culturas, acontecimentos do cotidiano e conhecimentos de distintas naturezas. A exploração dessas características e marcas demanda reconsiderar o currículo e as metodologias que colocam o aluno no centro do processo educativo e focam a aprendizagem ativa (p. 459).

Rodrigues (2001) considera a educação um processo integral de formação humana, norteado para a autonomia, a liberdade, a ética, a solidariedade e o reconhecimento da individualidade do outro, com propósitos correlacionados ao mundo da cultura. “Faz-se necessário ressignificar o próprio conceito de educação e seus modos de fazer diante da emergência da cultura digital, caracterizada pela relação ubíqua com as TDICs e o conhecimento" (VALENTE; ALMEIDA; GERALDINI, 2017, p. 458). A integração dessas tecnologias digitais na educação, contudo, precisa ser pensada de forma crítica, desenvolvendo autonomia e reflexão dos envolvidos e permitindo diferentes possibilidades de ensino. É nesse novo contexto educacional que o Ensino Híbrido se insere.

O modelo de Ensino Híbrido pressupõe um formato de aprendizagem que combina uma mistura entre o ensino on-line e o ensino presencial, conhecido como off-line ou face-to-face, em que se combinam momentos mediados pelas tecnologias digitais e momentos que envolvem elementos presenciais. Horn e Staker (2015, p. 34) definem o Ensino Híbrido como "qualquer programa educacional formal no qual um estudante aprende, pelo menos em parte, por meio do ensino on-line, com algum elemento de controle dos estudantes sobre o tempo, o lugar, o caminho e/ou ritmo". Combinam-se as práticas tradicionais na sala de aula presencial com aquelas que compreendem a integração das tecnologias digitais no espaço educacional, a fim de possibilitar diversas maneiras de aprender e que o estudante tenha possibilidade de desenvolver sua aprendizagem de modo autônomo (ALMEIDA, 2017). 
Staker e Horn (2012) explicitam quatro modelos usualmente utilizados pelos principais experimentos de Ensino Híbrido. São eles: modelos de rotação, modelo flex, modelo à la carte, e modelo virtual enriquecido. Os modelos mais oportunos ao contexto educacional brasileiro, conforme denotam Bacich, Tanzi Neto e Trevisani (2015), no entanto, trata-se dos modelos de rotação, em que os alunos alternam atividades a serem realizadas sob instrução ou não do professor, em períodos determinados de tempo. As ações podem envolver discussões em grupo, trabalhos escritos, leituras, e, ao menos, uma atividade digital (on-line). Esse estilo contempla a organização dos estudos por rotação por estações, sala de aula invertida e laboratório rotacional, formatos estes utilizados neste estudo.

No modelo de rotação por estações os estudantes organizam-se em equipes, e cada uma delas realiza uma atividade diferenciada em estações de trabalho de acordo com os objetivos da aula. Os estudantes percorrem todas as estações, alternando entre elas no tempo programado pelo professor. No formato de sala de aula invertida há uma inversão da sala de aula, em que as atividades comumente realizadas em casa são realizadas no espaço escolar. Deste modo, o aluno dedica-se fora do ambiente escolar (casa, biblioteca, lan house, laboratório) aos conteúdos no formato on-line, com o auxílio de vídeos, jogos, leituras, etc., enquanto o espaço da sala de aula é utilizado para discussões, resolução de atividades, entre outros. O terceiro modelo citado refere-se ao laboratório rotacional. Neste, os discentes usam tanto o espaço de sala de aula quanto o laboratório de informática ou outro espaço para a realização da aula, que contará com um ambiente on-line e um ambiente off-line; assim, um grupo de alunos desenvolverá a atividade on-line em laboratório, enquanto o outro grupo participará da aula na companhia do professor (MARTINS, 2016).

Esses modelos de organização do espaço escolar tornam o ambiente de aprendizagem mais dinâmico, cabendo ao estudante assumir uma postura mais participativa, possibilitando oportunidades autônomas de construção de seu conhecimento. A sala de aula passa a ser o local onde o aluno, na condição de aprendiz, na presença do professor e dos colegas, amplia seu pensamento crítico e desenvolve competências necessárias para viver em sociedade (VALENTE, 2015).

Por este motivo, diante da emergência em tratar a questão ambiental no ambiente escolar, estudá-la a partir de uma nova organização didática que combine a utilização de TDICs, por meio do Ensino Híbrido, pressupõe a possibilidade de sensibilização ecológica na prática pedagógica, que propicie um ambiente social mais crítico e integrado à realidade contemporânea. Sendo assim, este trabalho tem por objetivo investigar a organização da atividade didática no modelo de Ensino Híbrido, observando-se se proporciona condições adequadas para o despertar de um sujeito ecológico pautado na Educação Ambiental Crítica.

\section{TRAJETÓRIA DA PESQUISA}

O presente estudo é de caráter qualitativo, tendo em vista que são investigadas as relações entre os sujeitos participantes, os valores, as dimensões subjetivas e as reflexões da realidade observada. 
As pesquisas em educação caracterizam-se, essencialmente, como qualitativas, tendo em vista que se concentram em interpretar fenômenos e práticas educativas, buscando uma realidade diversa, dinâmica, complexa e específica, com o intuito de perceber a realidade educacional da forma mais complexa e holística possível. "[...] É preciso buscar para a sua interpretação, a totalidade, entendida como complexidade, do fenômeno social e humano; é preciso buscar as 'qualidades' dos processos educativos para compreendê-los".

Optou-se também pela utilização da pesquisa participante em virtude dos propósitos deste estudo, em especial em relação ao compromisso mútuo entre pesquisador e pesquisados. Nesse contexto, "a pesquisa é feita 'junto' e os pesquisados participam em todo o processo, deixando assim de serem 'objeto' para serem o 'sujeito' de pesquisa" (MADEIRA, 1987, p. 28). Esse modelo tem suas origens na filosofia da práxis, alicerçado no referencial epistemológico do materialismo dialético e histórico, o qual reconhece o homem em sua totalidade e potencialidade, para construir e transformar seu próprio contexto (GRAMSCl, 1978). Madeira (1987) salienta que vários estudos têm sido realizados com enfoque na pesquisa participante, destacando, sobremaneira, a ação educativa e a participação, objetivando sempre a mudança de consciência para uma visão crítica, que possibilite melhores condições de vida.

A pesquisa foi realizada com alunos do curso técnico em Informática de um colégio de educação profissional na Região Noroeste do Paraná, fundado em 2015, que conta atualmente com uma equipe de 32 servidores e 213 alunos matriculados nos cursos técnicos de Informática e Produção de moda, integrados ao Ensino Médio. Trata-se de uma instituição com diversos projetos envolvendo o uso de tecnologias e robótica, motivo que justifica a escolha desse curso e dessa instituição. Cabe assinalar que a investigação ocorreu com a autorização da direção e de todos os estudantes que participaram, voluntariamente, da pesquisa.

O processo de desenvolvimento desta proposta foi iniciado em outubro de 2017, e foram convidados para participar do curso intitulado "Meio Ambiente Conectado" 39 estudantes da turma mencionada, dos quais foram voluntários, efetivamente, 15 estudantes, com idades entre 14 e 15 anos, sendo 6 meninos e 9 meninas.

Para assegurar os princípios éticos, o trabalho foi submetido e aprovado pelo Comissão de Ética em Pesquisa (CEP) da Universidade Estadual de Maringá, por meio do registro CAAE: 78889417.7.0000.0104, e os estudantes e seus responsáveis apresentaram o Termo de Consentimento Livre e Esclarecido (TCLE).

Inicialmente, os alunos foram contatados por meio de uma conversa informal para explicar, de forma geral, a proposta da pesquisa. Os estudantes que aderiram ao projeto preencheram uma planilha com seus dados pessoais ${ }^{3}$ para contato (nome completo, número de telefone e e-mail), além de informações relacionadas ao acesso à internet fora do ambiente escolar. Tal solicitação foi importante para conhecer o perfil dos sujeitos e para que não ocorresse possibilidade de exclusão (no caso de algum dos alunos não ter as tecnologias propostas para utilização ao longo do curso).

${ }^{3} \mathrm{No}$ intuito de preservar a identidade deles, foram atribuídos pseudônimos. 
Como instrumento de coleta de dados, optamos pela organização de uma sequência didática (ZABALA, 1998). As sequências didáticas (SDs), também conhecidas como sequências de atividades de ensino/aprendizagem, são "um conjunto de atividades ordenadas, estruturadas e articuladas para a realização de certos objetivos educacionais, que têm um princípio e um fim conhecidos tanto pelos professores como pelos alunos" (ZABALA, 1998, p. 18).

Deste modo, o curso foi planejado com uma carga horária de 20 horas, distribuídas em quatro encontros semanais, combinando momentos presenciais (cerca de três horas por encontro) e a distância (cerca de duas horas por encontro), com o início programado para o dia 30 de outubro de 2017 e a conclusão para o dia 20 de novembro de 2017. Os conteúdos propostos basearam-se nos Parâmetros Curriculares Nacionais de Meio Ambiente (PCNs), subdivididos em três blocos: A Natureza Cíclica da Natureza, Sociedade e Meio Ambiente e Manejo e Conservação Ambiental.

No Quadro 1 apresenta-se como os encontros foram realizados: conteúdos, formato híbrido utilizado e recursos didáticos aplicados.

Quadro 1 - Sequência didática trabalhada no curso Meio Ambiente Conectado

\begin{tabular}{|c|c|c|c|c|}
\hline Encontros & Objetivos & Conteúdos & $\begin{array}{l}\text { Formato de sala de } \\
\text { aula }\end{array}$ & $\begin{array}{c}\text { Metodologia e } \\
\text { ferramentas }\end{array}$ \\
\hline 10 Encontro & $\begin{array}{l}\text { Permitir ao aluno } \\
\text { compreender que os } \\
\text { processos na natureza } \\
\text { não são estanques, } \\
\text { nem no tempo } \\
\text { tampouco no espaço. }\end{array}$ & $\begin{array}{l}\text { Natureza } \\
\text { "Cíclica" da } \\
\text { Natureza. }\end{array}$ & $\begin{array}{l}\text { Rotação por } \\
\text { estações e sala de } \\
\text { aula invertida. }\end{array}$ & $\begin{array}{l}\text { Tablet, } \\
\text { computadores, } \\
\text { smartphone, } \\
\text { livro, papel e } \\
\text { caneta. }\end{array}$ \\
\hline 20 Encontro & $\begin{array}{l}\text { Possibilitar a } \\
\text { compreensão das } \\
\text { relações entre a } \\
\text { sociedade e o meio } \\
\text { ambiente. }\end{array}$ & $\begin{array}{l}\text { Sociedade } \\
\text { e Meio } \\
\text { Ambiente. }\end{array}$ & $\begin{array}{l}\text { Laboratório } \\
\text { rotacional. }\end{array}$ & $\begin{array}{l}\text { Computadores; } \\
\text { apostila. }\end{array}$ \\
\hline 3을 Encontro & $\begin{array}{l}\text { Promover a } \\
\text { compreensão de } \\
\text { técnicas alternativas } \\
\text { para preservação e } \\
\text { tomadas de decisão em } \\
\text { relação aos recursos } \\
\text { naturais. }\end{array}$ & $\begin{array}{l}\text { Manejo e } \\
\text { Conservação } \\
\text { Ambiental. }\end{array}$ & $\begin{array}{l}\text { Rotação por } \\
\text { estações. }\end{array}$ & $\begin{array}{l}\text { Computadores, } \\
\text { smartphone, } \\
\text { papel e caneta. }\end{array}$ \\
\hline 40 Encontro & $\begin{array}{l}\text { Óscar do curso “Meio } \\
\text { Ambiente Conectado". }\end{array}$ & $\begin{array}{l}\text { Conteúdos } \\
\text { diversos } \\
\text { trabalhados } \\
\text { ao longo do } \\
\text { curso. }\end{array}$ & $\begin{array}{l}\text { Sala de aula } \\
\text { invertida. }\end{array}$ & $\begin{array}{l}\text { Projetor } \\
\text { multimídia. }\end{array}$ \\
\hline
\end{tabular}

Fonte: Elaborado pelos autores, 2018.

Para os procedimentos on-line foi utilizada a plataforma digital Edmodo, que é uma rede social educacional, a qual disponibiliza um ambiente virtual de aprendizagem para a interação da comunidade escolar. Para o desenvolvimento de ações com o uso 
das tecnologias, optou-se pelo espaço do laboratório de informática, tendo em vista que esse espaço já estava equipado com computadores e acesso à internet mediante wi-fi.

Para a coleta de dados foram empregadas as seguintes técnicas: rodas de conversa, diálogos, observações e vivência nas estações. Como instrumentos, em especial, foram usadas as gravações de áudio e vídeo, feitas com um smartphone, e os questionários e os registros dos estudantes, realizados por meio das atividades e dos comentários feitos nas ações presenciais e on-line.

Essas técnicas e esses instrumentos de coleta de dados permitiram definir o corpus da pesquisa e a reflexão acerca de como analisar as informações coletadas. O modelo de análise deveria valorizar as visões dos sujeitos da investigação e as diferentes formas de conteúdo, por isso optou-se pela análise de conteúdo. “[...] Trata-se de uma técnica de tratamento de dados, que visa à interpretação do material de modo qualitativo, assegurando uma descrição objetiva, sistemática e com a riqueza manifestada no momento da coleta" (GUERRA, 2014, p. 38).

Bardin (1977) organiza a técnica de análise de conteúdo em três fases: a) pré-análise; b) exploração do material; c) tratamento dos resultados, inferência e interpretação. Na fase de pré-análise ocorre a sistematização das ideias iniciais propostas no referencial teórico e são estabelecidos os indicadores para a interpretação das informações coletadas. Em outras palavras, organiza-se o material a ser investigado a fim de que o pesquisador possa conduzir as próximas operações de análise. Essa fase compreende: leitura flutuante, escolha dos documentos, formulação de hipóteses e objetivos e elaboração de indicadores.

\section{A COMPREENSÃO DO PROCESSO}

Conforme organização apresentada na metodologia, explica-se aqui como se desenvolveu cada encontro realizado ao longo do curso. De modo geral, ao longo da aplicabilidade da SD procurou-se centralizar os alunos durante todo o processo, a fim de que pudessem expressar e discutir as temáticas com seus pares, sendo considerado o cotidiano vivenciado por eles, seja no espaço escolar, seja em casa ou na comunidade, com o intuito de tornar a aprendizagem mais significativa.

Todas as atividades presenciais realizadas durante os encontros foram recolhidas pelos pesquisadores, que também registravam, em áudios e fotos, com seu smartphone, alguns momentos da aula. Por se tratar de uma pesquisa participante, em que o pesquisador participa das atividades interagindo com os sujeitos, não foi possível realizar a coleta de todas as falas. Também, para não gerar constrangimento nos sujeitos da pesquisa, optou-se por não convidar terceiros para realizar essas gravações.

Os dados utilizados foram coletados por meio de atividades, observações e questionários realizados durante as aulas, e de materiais produzidos on-line na plataforma de ensino Edmodo. É válido salientar que as práticas manuscritas e os áudios coletados foram transcritos literalmente. 
Para a organização das aulas houve uma fase inicial de planejamento, que foi sendo refeito à medida que as atividades aconteciam, conforme já mencionado. Em um primeiro momento, para o desenvolvimento do curso, ocorreu o diálogo informal com os 18 alunos inscritos, a fim de verificar quais eram suas expectativas quanto à participação nesse processo formativo e analisar o dia da semana mais adequado para a realização dos encontros presenciais.

O curso foi planejado com uma carga horária de 20 horas, mas os estudantes relataram que utilizaram um tempo maior para a produção das avaliações, em especial, a avaliação final, a qual será descrita adiante. Dessa forma, a carga horária do curso foi ampliada para 25 horas.

No que diz respeito às horas de planejamento, considerou-se uma carga horária de 40 horas para pesquisa e planejamento das aulas, escolha dos vídeos, elaboração de atividades presenciais e on-line, configuração da plataforma Edmodo, escolha das aulas disponíveis nas plataformas Geekie e Khan Academy, organização dos espaços, dentre outros aspectos. Para interagir com os participantes, além da plataforma Edmodo, foi criado um grupo de WhatsApp, canal mais utilizado para a definição dos encontros e os comunicados importantes, além de ter sido empregado para algumas atividades realizadas em sala.

No dia 10 de novembro de 2017 ocorreu o primeiro encontro. A proposta inicial continha nove estações de trabalho, porém, em razão da desistência de três estudantes, foram executadas sete estações. Os outros conteúdos foram incluídos nas demais estações, a fim de que as atividades objetivadas e o planejamento fossem mantidos.

Nesse dia, os 15 estudantes inscritos estavam presentes e, após a recepção deles, foi feita a apresentação do curso. Assim, foi possível explicitar a proposta de formação e como ocorreria o desenvolvimento das aulas por meio do Ensino Híbrido, a fim de que os participantes pudessem analisar e participar das decisões acerca do que seria desenvolvido com eles e para eles durante a formação.

Em seguida, os alunos reuniram-se em grupos, formando seis duplas e um trio. Esses grupos iniciaram a aula respondendo a um questionário sobre seus conhecimentos prévios em relação à EA e ao uso de tecnologias digitais. O questionário seria preenchido de forma on-line, por meio do Google formulário, porém, pela instabilidade de conexão, houve a disponibilização impressa para os estudantes.

Realizada essa primeira atividade, os participantes foram direcionados para as estações de trabalho, previamente identificadas com as indicações das atividades que deveriam ser desenvolvidas.

A primeira aula foi organizada no formato de rotação por estações, em que os alunos rotacionavam pelos espaços de trabalho.

As atividades desenvolvidas nessa primeira aula possibilitaram a abertura do diálogo sobre a temática ambiental aos participantes. Em diversos trechos das atividades e falas transcritas, foi possível identificar um olhar crítico dos estudantes em relação ao contexto socioambiental. Como exemplo, a seguir, há uma fala de João e Bela, que constatam sérios problemas ambientais na região. 
O crescente aumento de latifúndios na região e expansão de terrenos para construção de novas moradas acabam com a vegetação local que por consequência levará ao fim as espécies animais que vivem nela. Além dessa há uma proposta de extração de xisto na região, que se acontecer, desencadeará uma série de problemas ambientais (JOÃO e BELA).

Nesse primeiro momento os estudantes participaram efetivamente da proposta, demonstrando interesse no desenvolvimento das atividades. O formato de rotação por estações dinamizou o processo e possibilitou que vários conteúdos fossem explorados no espaço de tempo programado para a aula, que durou cerca de 180 minutos. A seguir, destaca-se a opinião das alunas Tereza e Luana acerca do desenvolvimento desse primeiro encontro.

A aula de hoje foi muito legal e diferente; eu amei! Nós aprendemos muitas coisas sobre o meio ambiente e a biodiversidade. As atividades foram feitas em duplas, onde cada dupla passou por oito estações (não me recordo direito). Em cada estação nós aprendíamos muito mais com a ajuda das tecnologias. Nós vimos vídeos, lemos textos e produzimos textos e frases. Sempre com a ajuda da professora que nos auxiliava em tudo e fazia muitas perguntas legais sobre o tema para nós. Foi muito legal! (TEREZA).

O modelo da aula foi bem interessante; havia estações e cada uma delas tinha um tema, alguma atividade para fazer e você aprendia algo novo com todas. Em algumas estações utilizamos nosso celular, em outras o computador e em outras o tablet. A professora nos auxiliou nas atividades, tirou dúvidas, etc. O papel das tecnologias nessa aula foi muito importante por que eu aprendi bem mais coisas na frente do computador do que se estivesse em uma aula "normal" na sala (LUANA).

O segundo encontro ocorreu no dia 6 de novembro de 2017, organizado no formato de laboratório rotacional. O desenvolvimento da aula foi marcado por discussões acerca do consumo sustentável, demonstrando reflexões sobre as ações de consumo desenvolvidas no contexto social dos participantes.

O consumo em nossa casa tem partes boas e ruins, pois consumimos em excesso e conseguimos economizar; por exemplo, reutilizarmos a água da chuva para lavar calçadas, roupas e nosso consumo em excesso e comprar além do necessário, pois às vezes compramos alimentos e acaba estragando, o consumo de energia que usamos muito (EMANUELLY e TONY).

Se todos tivessem a oportunidade de perceber o porquê de consumirmos tanto, os motivos pelos quais somos incentivados a consumir e as consequências desse consumo exagerado, recursos seriam utilizados de forma não exagerada e sustentável, portanto creio que para diminuir os impactos ambientais urbanos devemos abrir a mente das pessoas e fazer com que elas enxerguem esse sistema todo que está por trás do que consumimos (FERNANDA).

Dentre as citações elencadas, os alunos retratam observações do bairro onde residem, das ações do poder público e do descarte incorreto de resíduos em sua escola, refletindo o olhar crítico sobre o ambiente em que estão inseridos. 
Em relação aos conteúdos on-line, os alunos possuíam o prazo de uma semana para a realização das atividades, porém nem todos realizaram no tempo hábil. Quando questionados sobre o porquê da não realização, as respostas foram diversas: problemas com a internet; o computador apresentou problemas; esquecimento; falta de tempo para realização concomitante com as demais atividades escolares.

Dentre as atividades realizadas há a história em quadrinhos, feita pelos alunos Luan e Renato, que contempla os conteúdos estudados. A referida tarefa originou-se da seguinte questão disponibilizada no Edmodo: baseando-se nos conhecimentos adquiridos durante as aulas, crie uma história em quadrinhos (você pode utilizar o celular, o computador ou pode fazer à mão) que possa levar informação e conhecimento ao leitor. Essa história deve ser compartilhada aqui, para que seus colegas leiam e comentem.

O terceiro encontro ocorreu no dia 13 de novembro de 2017, também no formato de rotação por estações. Para esse encontro foram programadas três estações de trabaIho, com os conteúdos contemplados no tópico Manejo e Conservação Ambiental, seguidos de um campeonato de gestão de recursos hídricos, por meio do jogo digital Água em Jogo, ${ }^{4}$ disponibilizado pela Agência Nacional de Águas do Brasil (ANA). Em virtude, porém, da instabilidade de conexão com a internet, não foi possível realizar a ação programada. Por esse motivo, o tempo destinado à realização dessa atividade foi preenchido com o início da preparação do trabalho avaliativo final do curso, que compreendeu a produção de um documentário sobre os temas de EA, conforme já explicitado.

No decorrer na terceira aula os estudantes refletiram sobre as problemáticas observadas no ambiente escolar. Renato e Luan destacaram algumas falhas identificadas, as quais estão expostas a seguir.

Nosso campus sofre muito com o efeito de ilhas de calor. Até pouco tempo não tínhamos árvores plantadas e as que foram plantadas ainda vão demorar para crescer. $O$ consumo de energia no campus também é muito alto, com ar condicionados, muitos eletrônicos ligados o dia inteiro. Também temos um grande desperdício de água por conta de falta de manutenção nos bebedouros e vazamentos que, além de desperdiçar água, causam goteiras nada agradáveis. Em nossos espaços de convivência temos falta de separação de lixo, tendo apenas dois lixos - um para lixo orgânico e outro para o restante -, em que se misturam todos tipos de reciclável e não reciclável (RENATO e LUAN).

Outros participantes, como Manoel e Luana, abordaram a necessidade de compreensão dos problemas ambientais reconhecidos no ambiente escolar. Nas palavras desses alunos, "há políticas sustentáveis implantadas em nossa escola, entretanto esses programas são criados, mas na prática não funcionam, por conta da falta de conscientização das pessoas".

\footnotetext{
${ }^{4}$ Trata-se de um jogo digital que simula a gestão dos recursos hídricos em uma bacia hidrográfica durante quatro anos fictícios. Os níveis de qualidade e quantidade de água devem ser acompanhados em todo o tempo. O game pode ser utilizado por professores em sala de aula para ministrar temas como água, meio ambiente, poluição, bacia hidrográfica, administração de recursos financeiros, mediação de conflitos, dentre outros. O jogo possibilita a criação de um campeonato, em que se atribui um ranking de pontuação (ANA, 2014).
} 
Durante a aula foi possível observar que os estudantes trabalharam bem em equipe, fomentando discussões e debates adequados para a temática ambiental. Diversos discursos apresentaram sensibilidade ao reconhecerem que as atitudes humanas provocam danos ao meio ambiente, mas que, com conhecimento, esse quadro pode se tornar uma nova realidade.

O quarto encontro foi marcado pelo encerramento do curso e pela atividade avaliativa final. Nesse sentido, observou-se que uma semana para a produção dos documentários seria um tempo insuficiente, em razão das demais atividades acadêmicas dos estudantes. Por esse motivo, em conjunto com os participantes, ficou definido que o dia ideal para apresentação dos trabalhos seria 4 de dezembro de 2017. No início dessa aula, os grupos foram questionados em relação ao processo de pesquisa, à produção, à edição do vídeo e a como se sentiram sendo pesquisadores. Algumas respostas estão transcritas a seguir.

A gente tentou bolar um esquema de que, por exemplo, a redução de lixo; a destinação correta dele está presente na vida de todo mundo, entendeu? Então a gente falou assim, a gente montou um esquema, vamos falar com as crianças, com... os pré-adolescentes e com os adultos, para ver a concepção deles sobre esse tema. Porque cada um tem uma... uma forma de pensar, uma maneira de pensar, entendeu? (MANOEL).

E daí a gente buscou tipo... conversar com pessoas diferentes, com conhecimentos diferentes tipo... do que cada pessoa pensa. Tipo assim, eles responderam coisas totalmente diferentes e... tudo no mesmo assunto [...] por isso que a gente aprendeu bastante coisa, né? (DORA).

Em relação aos documentários, é possível destacar os seguintes aspectos:

- em geral, os vídeos foram produzidos de forma satisfatória, demonstrando comprometimento dos alunos em todo o processo, em especial, na construção dos roteiros.

- em alguns vídeos os estudantes realizaram pesquisa de campo e ouviram pessoas de outras escolas (professores, crianças e comunidade) para subsidiar o processo de produção.

- em todo o tempo foi preciso dar suporte aos alunos, tanto na sugestão de materiais de pesquisa quanto nas dúvidas sobre como fazer o trabalho. $O$ suporte foi realizado presencialmente e on-line, por meio do WhatsApp e da plataforma Edmodo.

A banca, composta por professores de Biologia, Língua Portuguesa e Artes, ficou encarregada de escolher o melhor documentário, avaliando itens como linguagem, conhecimentos específicos e aspectos audiovisuais. Todos os trabalhos foram organizados com empenho e dedicação, mas um se sobressaiu, pois apresentou maior domínio quanto à pesquisa, referenciou as fontes pesquisadas e usou uma linguagem clara e objetiva. Apesar disso, vale destacar que todos os documentários deveriam ser premiados.

\section{RESULTADOS E DISCUSSÃO}

De forma geral, o curso desenvolvido no modelo de Ensino Híbrido proporcionou aos estudantes uma visão ampla da questão ambiental, fomentada, principalmente, por meio das discussões e do emprego das tecnologias e plataformas. Apesar disso, os 
conteúdos trabalhados poderiam ter um aprofundamento teórico maior, no sentido de ampliar a visão dos estudantes para as questões sociais presentes nas discussões educacionais modernas de EA.

Nesse sentido, é válido salientar que os participantes demonstraram aprendizado e reflexão ante os conteúdos estudados, sem dificuldades relacionadas à utilização das tecnologias digitais ao longo do curso. Além disso, em diversos relatos foi possível reconhecer que o curso proporcionou uma ampliação da maneira como os alunos visualizam a sala de aula e a necessidade de alteração de certos hábitos em prol de um meio ambiente mais saudável. Nessa perspectiva, a aluna Bruna expõe:

o curso "Meio Ambiente Conectado" foi muito satisfatório, em minha opinião. Aprendi que para aprender não precisamos usar aquele "modelo" de sala com um professor na frente e alunos enfileirados. E também que devemos conservar o meio ambiente e a natureza, pois nosso futuro e das gerações futuras dependem disso.

Apesar dos resultados positivos, surgiram algumas adversidades ao longo da trajetória de pesquisa e durante a realização do curso Meio Ambiente Conectado, que serão tratadas de forma mais explícita. De modo sintético, os principais percalços encontrados foram:

- Incompatibilidade de horários dos participantes. Houve dificuldade para escoIher o dia da semana para o início das atividades do curso, tendo em vista que os estudantes participam de outros projetos, em contraturno, na instituição.

- Conexão com a internet. Em diversos momentos a internet apresentou lentidão ou ficou inoperante e, por esses motivos, algumas atividades foram replanejadas.

- Tempo planejado. Apesar do planejamento em relação ao tempo necessário para o desenvolvimento das atividades nas estações de trabalho, em alguns momentos esse tempo foi insuficiente e, em outros, houve folga. Além disso, nem todos os grupos realizavam as atividades com o mesmo tempo de duração.

- Deficiência no cumprimento das atividades solicitadas. Alguns estudantes tiveram dificuldades para cumprir as atividades propostas no ambiente on-line.

- Tempo necessário para o planejamento das aulas. A diversidade de atividades e estações de trabalho requer que o professor tenha tempo suficiente para planejar e preparar antecipadamente os encontros e os espaços para a execução das aulas.

Essas questões influenciaram a concretização de algumas ações, mas não impediram o desenvolvimento delas. Com base nos dados coletados, apresenta-se a organização do processo de desmontagem dos textos e falas transcritos, a descrição e a interpretação dessas categorias.

Conforme expõem Silva e Fossá (2015, p. 7), “a opção pela análise categorial se respalda no fato de que é a melhor alternativa quando se quer estudar valores, opiniões, atitudes e crenças, através de dados qualitativos". Nesse âmbito, as categorias iniciais configuram-se como as primeiras impressões acerca da realidade estudada. Re- 
sultou do processo de categorização das atividades e falas transcritas um total de 23 categorias iniciais, que forneceram suporte para as próximas categorias, ou seja, as intermediárias. Cada categoria foi constituída pelos trechos levantados e com o respaldo do referencial teórico.

Inicialmente, as seis categorias intermediárias emergiram do agrupamento das 23 categorias iniciais, mas a constituição final foi formada por duas categorias, denominadas "Sensibilização crítica e mudança de postura ante os danos ambientais provocados pelas ações humanas que comprometem o futuro da humanidade" e "Tecnologias dinamizam e facilitam o processo de aprendizagem", como exposto no Quadro 2.

\section{Quadro 2 - Categorias de análise criadas a partir das redações dos alunos participantes} do curso Meio Ambiente Conectado

\begin{tabular}{|c|c|c|c|}
\hline Iniciais & Intermediárias & Finais & Frequência \\
\hline 0. Compreensão sobre o meio ambiente. & \multirow{8}{*}{$\begin{array}{l}\text { Compreensão sobre o } \\
\text { meio ambiente. }\end{array}$} & \multirow{15}{*}{$\begin{array}{l}\text { I) Sensibilização } \\
\text { crítica e } \\
\text { mudança de } \\
\text { postura ante } \\
\text { os danos } \\
\text { ambientais } \\
\text { provocados } \\
\text { pelas ações } \\
\text { humanas e que } \\
\text { comprometem } \\
\text { o futuro da } \\
\text { humanidade. }\end{array}$} & \multirow{15}{*}{136} \\
\hline 1. Evolução do planeta. & & & \\
\hline 2. Redução dos danos ambientais. & & & \\
\hline 3. Redução e correta destinação do lixo. & & & \\
\hline 4. Problemas socioambientais urbanos. & & & \\
\hline 5. Importância da água. & & & \\
\hline $\begin{array}{l}\text { 6. Risco das queimadas para o meio } \\
\text { ambiente. }\end{array}$ & & & \\
\hline 7. Importância da biodiversidade. & & & \\
\hline $\begin{array}{l}\text { 8. Meio ambiente e qualidade de vida no } \\
\text { presente e no futuro. }\end{array}$ & \multirow[t]{4}{*}{$\begin{array}{l}\text { Reflexão sobre o futuro } \\
\text { da humanidade. }\end{array}$} & & \\
\hline 9. Compreensão sobre a sustentabilidade. & & & \\
\hline 10. Consumo sustentável. & & & \\
\hline 11. Relação sociedade/natureza. & & & \\
\hline $\begin{array}{l}\text { 12. Responsabilização pelo futuro da } \\
\text { humanidade. }\end{array}$ & \multirow{3}{*}{$\begin{array}{l}\text { Senso crítico } \\
\text { sobre a realidade } \\
\text { socioambiental local. }\end{array}$} & & \\
\hline $\begin{array}{l}\text { 13. Problemas ambientais que afetam sua } \\
\text { comunidade, escola e região. }\end{array}$ & & & \\
\hline $\begin{array}{l}\text { 14. Mudança de postura em relação ao meio } \\
\text { ambiente e à sociedade. }\end{array}$ & & & \\
\hline 15. Uso de tecnologias para estudo. & \multirow{4}{*}{$\begin{array}{l}\text { Utilização das } \\
\text { tecnologias para } \\
\text { aprendizagem. }\end{array}$} & \multirow{8}{*}{$\begin{array}{l}\text { II) As tecnologias } \\
\text { digitais } \\
\text { integradas } \\
\text { à prática } \\
\text { pedagógica } \\
\text { dinamizam } \\
\text { e facilitam o } \\
\text { processo de } \\
\text { aprendizagem. }\end{array}$} & \multirow{8}{*}{59} \\
\hline $\begin{array}{l}\text { 16. As tecnologias como facilitadoras de } \\
\text { aprendizagem. }\end{array}$ & & & \\
\hline $\begin{array}{l}\text { 17. Vantagens e desvantagens do uso de } \\
\text { tecnologias na escola. }\end{array}$ & & & \\
\hline $\begin{array}{l}\text { 18. Uso de plataformas multimídia e } \\
\text { aplicativos digitais no processo de ensino. }\end{array}$ & & & \\
\hline $\begin{array}{l}\text { 19. Ser responsável e autônomo no processo } \\
\text { de ensino. }\end{array}$ & \multirow{2}{*}{$\begin{array}{l}\text { Mudança do papel } \\
\text { do estudante e do } \\
\text { professor no processo } \\
\text { de ensino. }\end{array}$} & & \\
\hline $\begin{array}{l}\text { 20. Professor como mediador da } \\
\text { aprendizagem. }\end{array}$ & & & \\
\hline $\begin{array}{l}\text { 21. Alteração do formato de sala de aula - } \\
\text { tradicional ou híbrido. }\end{array}$ & \multirow[t]{2}{*}{$\begin{array}{l}\text { Formato de sala de } \\
\text { aula. }\end{array}$} & & \\
\hline 22. Trabalho em equipe. & & & \\
\hline
\end{tabular}


Como mencionado anteriormente, a última fase da análise de conteúdo (BARDIN, 1977) refere-se ao processo de interpretação dos dados. As categorias definidas apresentam o direcionamento para a compreensão dos aspectos da pesquisa a partir de descrições, discussões e interpretações.

A primeira categoria, "Sensibilização crítica e mudança de postura ante os danos ambientais provocados pelas ações humanas e que comprometem o futuro da humanidade", refere-se à importância do discurso ambiental no contexto educativo. Essa categoria tem o objetivo de formar estudantes para a cidadania, mobilizados por uma postura ética e atuante em relação aos problemas ambientais.

Na segunda categoria, "As tecnologias digitais integradas à prática pedagógica dinamizam e facilitam o processo de aprendizagem", discute-se a relevância das tecnologias no contexto educativo, transformando a sala de aula em um espaço mais interativo e dinâmico, o que contribui para o processo de ensino e aprendizagem. Essas discussões serão explicitadas nas próximas subseções, cujos títulos representam as categorias que surgiram ao longo da análise de conteúdo.

As unidades de registro que contêm a reflexão relacionada à sensibilização crítica dos estudantes sobre a problemática ambiental foram as mais presentes nos dados observados, sendo mencionadas em 136 registros, como exemplificam os seguintes trechos:

[...] devemos ter consciência que precisamos fazer de tudo para não poluirmos o ar, pois fará mal para nós mesmos (TEREZA).

[...] é preciso ser feito muitas coisas, como, por exemplo, a diminuição da poluição, ou seja, quando ver que o vizinho está queimando lixo dá pra alertá-lo dos prejuízos (TONY).

[...] devemos cuidar do nosso planeta e também das coisas que ele nos proporciona (ADRIANA).

[...] são coisa que você pode mudar no seu cotidiano; é fácil e você não precisa fazer nenhuma mudança (MANOEL).

Essas afirmações denotam que os estudantes compreenderam a importância de uma mudança de postura diante dos problemas ambientais e do futuro da humanidade. Essa reflexão parte do pressuposto de que a educação propicia "a modificação de valores humanos, buscando uma melhoria de vida de todos os habitantes do planeta, mas sempre respeitando a natureza e os seus elementos" (SHUNEMANN; ROSA, 2010, p. 123).

Essas categorias foram reunidas tendo em vista que refletem os pressupostos dos PCNs (BRASIL, 1997) e da EA crítica, destacando que, mais do que ensinar conceitos, é preciso contribuir para a formação de cidadãos conscientes, os quais possam atuar na realidade socioambiental de modo comprometido com o bem-estar de todos. Além disso, é preciso garantir aos estudantes uma "aprendizagem que Ihes possibilite posicionar-se em relação às questões ambientais nas suas diferentes realidades particulares e atuar na melhoria de sua qualidade" (BRASIL, 1997, p. 202). 
Tal posicionamento pode ser verificado neste trecho: "nós temos que ter um pouco de consciência né, que isso pode causar um efeito muito ruim para o nosso meio ambiente, e preservar mais, cuidar mais do que é nosso, nosso futuro né" (BRUNA). Nesse sentido, conforme expõem Pelicioni e Philippi Junior (2014), a EA pressupõe formar cidadãos para uma reflexão crítica e uma ação social transformadora, a fim de desenvolver o ser humano integralmente.

Nesse contexto, as escolas devem trabalhar a EA para provocar mudanças nas atitudes e nos valores dos estudantes. Corroborando, Polli e Signorini (2012) argumentam que a EA deve se propor a atingir todos os cidadãos por meio de um processo permanente e participativo, incutindo no aluno uma consciência crítica sobre os problemas ambientais, a fim de criar nesses estudantes um sentimento capaz de conscientizá-los para uma transformação social.

Os trechos destacam a sensibilização dos estudantes quanto às problemáticas ambientais e a necessidade de uma mudança de postura, salientando que as ações humanas podem intervir na realidade historicamente instituída pelos próprios seres humanos. Nessa perspectiva, segundo Carvalho (2012), formar um sujeito ecológico significa possibilitar a sensibilização de cidadãos capazes de compreender o mundo e agir nele de forma crítica, ecológica e social.

Esses dados, no entanto, apresentam poucas reflexões sobre as questões sociais presentes nos debates contemporâneos acerca da Educação Ambiental. Essa constatação pode ser atribuída a um contexto histórico de EA voltado, em especial, para o caráter ecologista do meio ambiente, desvencilhado de questões políticas e sociais. Assim, é importante que a EA focalize a relação entre o ser humano, a natureza e o universo, em uma perspectiva holística, com os olhos abertos para o esgotamento dos recursos naturais, provocado pelo homem, contemplando, acima de tudo, conforme expõe Jocobi (2003, p. 189), "um ato político voltado para a transformação social".

Os registros contendo trechos em que os estudantes manifestam a utilização de um novo formato de ensino, no qual as tecnologias estão integradas, estão presentes em 59 unidades de registro identificadas. Dentre as transcrições, é possível destacar as seguintes:

[...] tivemos ótimas aulas e bem interativas por causa das tecnologias utilizadas. Aprendi inúmeras coisas que não sabia e imaginava sobre a natureza (DORA).

[...] a professora nos propôs uma atividade bem interessante: nós íamos trocando de estação pela sala, o que tornava aquela atividade mais interessante (BRUNA).

[...] o professor deixou a gente autônomo; fizemos atividades sozinhos; isso foi importante para mostrar o que sabemos até aquele momento (IAGO).

[...] o fato de ser em dupla facilitou porque tivemos que discutir o assunto, ajudando um ao outro (IAGO).

[...] a tecnologia foi algo fundamental para nossa aula; temos várias plataformas para nos ajudar (LUAN).

Esses registros denotam a aplicação e a organização da atividade didática com o uso de tecnologias digitais, conforme preceitos do Ensino Híbrido. As categorias emergentes a partir desses dados abarcam a teoria estudada e os preceitos delineados pelo 
Ensino Híbrido, que pressupõe a combinação entre tecnologias e sala de aula tradicional, com, no mínimo, um elemento de controle aos estudantes, o qual permite ajustar a rotina de aprendizagem e no qual o aluno seja o centro do processo de ensino. Trata-se de um conjunto de propostas "[...] que unidas formam uma metodologia inovadora, cujo objetivo é inserir o estudante no aprendizado, tirando-o do estado de passividade e atribuindo-lhe um papel fundamental na construção do seu próprio conhecimento" (CAVERSAN, 2016, p. 40). As tecnologias foram aliadas do processo de ensino, com práticas pedagógicas diferenciadas, utilizadas a partir de um planejamento prévio e em conformidade com os objetivos delineados pela professora.

Os discursos dos estudantes denotam o interesse pela prática pedagógica, pois muitos relatam que a aula no formato híbrido proporcionou uma aprendizagem mais divertida, dinâmica, com maior autonomia, dentre outros aspectos. Esse interesse está presente nas mudanças significativas no perfil dos estudantes pertencentes a uma geração que nasceu imersa nas tecnologias digitais. Diante disso, as TDICs devem ser encaradas como ferramentas pedagógicas no contexto escolar, uma vez que essa geração tem uma relação natural com essas ferramentas, potencializando o ensino e a aprendizagem (CAVERSAN, 2016).

Nesse contexto, Moran (2012, p. 52) argumenta que as tecnologias têm um grande potencial nas práticas educativas, como "pontes que abrem a sala de aula para o mundo". Apesar, todavia, de ampliarem as possibilidades e melhorarem o processo de ensino e aprendizagem, as tecnologias não podem ser consideradas a cura para a educação (SASSAKI, 2016). Assim, Casali (2013) aponta os cuidados que o professor deve ter ao inserir a tecnologia em sua metodologia pedagógica, pois,

essa mudança radical na presença e no poder das tecnologias na vida econômica, social e cultural cotidiana intensificou o que desde a invenção da máquina a vapor se prenunciava: as tecnologias aparecem como se fossem dotadas de uma força autônoma e independentes dos processos que as produziram. Aparecem como fetiche. São os seres humanos quem as produz, mas, uma vez produzidas e entrando em operação, elas lhes parecem estranhas, como se fossem dotadas de vida própria. A construção do fetiche anula o reconhecimento do trabalho como origem substancial (produtor) das tecnologias e dos conhecimentos a elas inerentes. Essa fetichização, no caso das tecnologias contemporâneas da informação e da comunicação, cumpre a função ambivalente de, por um lado, agregar atratividade e valor a seu uso, o que pode ser bom para sua inclusão no universo pedagógico - pois, quando isso é bem feito, o uso das tecnologias resulta em potencialização da qualidade da educação - e, por outro lado, funcionam como o efeito de ocultamento de outros interesses em sua produção e disseminação: os interesses do mercado (p. 284).

Além desses cuidados, é importante que a inclusão das tecnologias na prática escolar seja planejada e, de fato, integrada ao currículo, não apenas como uma ferramenta interativa, mas para que possa contribuir com o processo educacional. De acordo com Caversan (2016), a introdução da tecnologia deve ser planejada, mensurada e organizada, de maneira que o docente se sinta seguro ao utilizar esse recurso e que torne a aprendizagem relevante para o estudante. 
No que se refere à Educação Híbrida, ela foi satisfatória para o processo de ensino de EA, do ponto de vista do estudante e da diversidade de ações possibilitadas, em especial pelo formato de rotação por estações. É preciso salientar, contudo, que as limitações estruturais, o tempo para organização e planejamento das aulas e a falta de comprometimento dos estudantes com atividades realizadas em casa, tornaram o processo desafiador.

Com base nos relatos das observações dos pesquisadores e nos relatos dos estudantes, acredita-se que a combinação dos modelos de Ensino Híbrido proporciona, de fato, autonomia, reflexão crítica e raciocínio reflexivo, além de oportunizar o trabalho em equipe, a cooperação e a colaboração. Do ponto de vista do professor, no entanto, a prática apresenta dificuldades, sobretudo no que diz respeito à operacionalização das tecnologias digitais, à infraestrutura das escolas, ao tempo de planejamento das aulas e ao modelo de rotação por estações. Apesar desses pontos negativos, sem dúvida, a aplicabilidade é fascinante.

\section{CONSIDERAÇÕES FINAIS}

Para dar início às considerações finais deste estudo, é preciso retomar o intuito desta pesquisa de analisar se a organização da atividade didática no modelo de Ensino Híbrido proporciona condições adequadas para o despertar de um sujeito ecológico, pautado na Educação Ambiental Crítica. As respostas, que emergiram ao longo da coleta de dados, evidenciaram as compreensões dos sujeitos participantes e proporcionaram novas inquietações.

Ao longo deste trabalho procurou-se esmiuçar a literatura que envolve a inclusão das tecnologias digitais na prática pedagógica, os aspectos que permeiam o Ensino Híbrido e a Educação Ambiental Crítica, a fim de propor a organização de uma SD que provocasse uma sensibilização dos envolvidos, para que eles pudessem repensar sua atuação enquanto membros da sociedade e responsáveis pelo ambiente que os cerca.

De maneira geral, as concepções dos estudantes demonstraram a necessidade de aprofundamento no debate em torno da Educação Ambiental. Tal entendimento decorre dos dados coletados e da visão naturalista de meio ambiente apresentada pelos alunos. Destarte, apesar da tentativa de fazê-los considerar, durante o curso, a amplitude da percepção ambiental, o que se percebeu foram discursos que denotam apenas o contexto ecológico de meio ambiente, eximidas as questões sociais que cercam esse contexto, tão importante para o debate contemporâneo.

No que diz respeito ao emprego do Ensino Híbrido, apesar da receptividade dos estudantes quanto à utilização das tecnologias integradas às atividades pedagógicas e dos benefícios educacionais proporcionados pelas diversas tecnologias, nesse caso tablets, computadores, smartphones e plataformas digitais (Edmodo, Geekie, Khan Academy), a proposta requer maior comprometimento por parte dos envolvidos, docente e discentes, infraestrutura adequada (espacial e equipamentos), melhor conexão de internet e envolvimento da comunidade escolar. 
A organização das aulas no modelo Híbrido, aplicado durante os quatro encontros presenciais e nas atividades on-line, mostrou-se adequada para o ensino de EA com o grupo participante. Salienta-se, no entanto, que a proposta foi realizada em uma instituição de ensino com condições propícias para essa aplicação: os discentes e a professora pesquisadora têm à disposição (e o domínio das) tecnologias; a instituição oferece bons laboratórios de informática e conexão com a internet; os estudantes estão adaptados às atividades em contraturno; dentre outros aspectos.

É válido ressaltar que essa não é uma característica de todas as escolas e de todos os estudantes e docentes. O que se observa, na maioria dos espaços escolares, são dificuldades estruturais, deficiência de equipamentos tecnológicos e internet, ausência de atividades de capacitação docente voltadas para a utilização de recursos tecnológicos, dentre outros problemas. Ainda, convém mencionar a carga horária docente excessiva, o que, muitas vezes, impossibilita a participação em propostas que requerem um planejamento mais elaborado, com a utilização de recursos didáticos diversos, além da falta de incentivo e da desvalorização desses profissionais.

Mesmo diante desse cenário marcado por desafios, todavia, proporcionar esse ambiente educacional para a aprendizagem de EA torna o processo lúdico e amplia a participação e a visão crítica dos alunos por meio dos mais variados instrumentos midiáticos, proporcionados por momentos presenciais e on-line. Há, portanto, uma experiência híbrida de aprendizagem ativa e integrada.

Apesar de esse modelo instigar maior participação discente na prática pedagógica, o papel do professor permanece essencial. É preciso que o docente seja um mediador do processo de ensino e aprendizagem, um interlocutor que problematiza, instiga a curiosidade e inspira o aluno na construção do saber crítico, participante de seu contexto social, desapegado de posturas apenas reprodutoras e receptoras de informação.

No que se refere à aplicação desta pesquisa, ambicionava-se que os participantes se sentissem motivados em todas as ações e que as atividades planejadas fossem, realmente, realizadas conforme programado. Como em qualquer trajetória educacional, no entanto, nem sempre tudo ocorre como previsto. No caso desta pesquisa, as conexões de internet apresentaram falhas, a estrutura espacial não atendeu às necessidades, os estudantes não realizaram as atividades no tempo esperado e as datas planejadas precisaram ser alteradas.

Considerando o que foi idealizado e as dificuldades encontradas, se fosse possível refazer todo o processo a distribuição da carga horária e, consequentemente, a distribuição dos conteúdos selecionados poderia ser reconsiderada, e seria disponibilizado um volume menor de atividades para o ambiente on-line. Isso porque, como era um curso realizado no contraturno, o volume de atividades, associado aos demais trabalhos escolares, sobrecarregou os estudantes.

Mesmo diante das dificuldades, entretanto, a aplicabilidade desse modelo de ensino apresentou-se satisfatória. Quando se integra as tecnologias à sala de aula, abre-se um leque de oportunidades que possibilitam a reflexão do aluno sobre o desconhecido e a vivência de experiências ricas e ativas de aprendizagem, mediadas pelas tecnologias integradas ao ambiente educativo. 
No contexto desta pesquisa, os caminhos percorridos foram além. A sensibilização sobre a temática ambiental refletiu-se nas ações dos estudantes, nas falas, nos debates e nas reflexões, posto que as tecnologias digitais foram o recurso de potencialização desse processo de ensino. A ideia de um ambiente novo e desafiador de aprendizagem torna o processo mais atrativo e interessante. Desse modo, o "divisor de águas" foi a utilização da metodologia híbrida, mobilizando os estudantes para uma aprendizagem autônoma, ativa e inovadora.

Este estudo possibilitou os primeiros passos para a formação de sujeitos ecológicos, com estilos de vida sustentáveis e sensibilidade ambiental. Apesar, entretanto, dessa compreensão, ainda há muito o que se avançar nas práticas de Educação Ambiental para possibilitar uma aprendizagem que provoque uma crítica à ordem social vigente, baseada na exploração dos bens ambientais e na manutenção das desigualdades sociais.

Nesse sentido, a partir desta pesquisa, é possível fazer os seguintes questionamentos: Qual foi o impacto do curso de Educação Ambiental no contexto social dos estudantes? Qual é a visão docente sobre o ensino de EA na perspectiva do Ensino Híbrido? Como os educadores têm utilizado as tecnologias digitais de informação e comunicação no contexto educativo? Esses questionamentos indicam a necessidade de novas investigações que abarquem essas e outras questões.

\section{REFERÊNCIAS}

ALMEIDA, A. N. Formação continuada de professores de matemática na perspectiva do ensino híbrido. 2017. Dissertação (Mestrado em Ensino Tecnológico) - Instituto Federal do Amazonas, Manaus, 2017. Disponível em: http://mpet.ifam.edu.br/dissertacoes-defendidas/. Acesso em: 10 mar. 2018.

BACICH, L. Ensino híbrido: personalização e tecnologia na educação. Tecnologias, Sociedade e Conhecimento, Campinas, v. 3, n. 1, dez. 2015. Disponível em: http://www.nied.unicamp.br/ojs/. Acesso em: 1은 mar. 2018.

BACICH, L.; TANZI NETO, A.; TREVISANI, F. de M. (org.) Ensino híbrido: personalização e tecnologia na educação. Porto Alegre: Penso, 2015.

BARDIN, L. Análise de conteúdo. Lisboa: Edições 70, 1977.

BRASIL. Secretaria de Educação Fundamental. Parâmetros curriculares nacionais: meio ambiente, saúde. Brasília, 1997. Disponível em: http://portal.mec.gov.br/seb/arquivos/pdf/livro091.pdf. Acesso em: 2 fev. 2018.

BRASIL. Ministério da Educação. Secretaria de Ensino Fundamental. Parâmetros Curriculares Nacionais. Brasília, 1998. Disponível em: http://portal.mec.gov.br/seb/arquivos/pdf/livro01.pdf. Acesso em: 2 fev. 2018.

BRASIL. Lei no 9.795, de 27 de abril de 1999. Dispõe sobre a educação ambiental, institui a Política Nacional de Educação Ambiental e dá outras providências. Diário Oficial da União. Disponível em: http://www. planalto.gov.br/ccivil_03/leis/L9795.htm. Acesso em: 21 nov. 2018.

CARVALHO, I. C. M. As transformações na cultura e o debate ecológico: desafios políticos para a educação ambiental. In: NOAL, F. O.; REIGOTA, M.; BARCELOS, V. H. L. (org.). Tendências da educação ambiental brasileira. Santa Cruz do Sul: Edunisc, 1998.

CARVALHO, I. C. Educação ambiental: a formação do sujeito ecológico. São Paulo: Cortez, 2012.

CASALI, A. Ética e tecnologias no currículo: fundamentos para políticas e práticas. In: VALLE, L. E. L. R. do; MATTOS, M. J. V. M. de; COSTA, J. W. da (org.). Educação digital: a tecnologia a favor da educação. Porto Alegre: Penso, 2013.

CAVERSAN, R. H. de M. Explorando o ensino híbrido em física: uma proposta para o ensino de fenômenos ondulatórios utilizando ferramentas multimidiáticas. 2016, 166f. Dissertação (Mestrado em Ensino de Física) - Universidade Estadual Paulista, Faculdade de Ciências e Tecnologia, Presidente Prudente, 2016. Disponível em: https://repositorio.unesp.br/handle/11449/148578. Acesso em: 5 mar. 2018. 
GOMES, R. W. Por uma educação ambiental crítica/emancipatória: dialogando com alunos de uma escola privada no município de Rio Grande/RS. Revista Ciência e Natura, Santa Maria, v. 36, n. 3, p. 430-440, set./ dez. 2014. Disponível em: https://webcache.googleusercontent.com/search?q=cache:dN5v-58IWDEJ:https://periodicos.ufsm.br/cienciaenatura/article/download/13171/pdf+\&cd=1\&hl=pt-BR\&ct=clnk\&gl=br. Acesso em: 22 abr. 2018.

GRAMSCI, A. Introdução à filosofia da práxis. Lisboa: Antídoto, 1978.

GUERRA, E. L. de A. Manual de pesquisa qualitativa. Belo Horizonte: Grupo Ănima Educação, 2014.

HORN, M. B.; STAKER, H. Blended: usando a inovação disruptiva para aprimorar a educação. Porto Alegre: Penso, 2015.

JOCOBI, P. Educação ambiental, cidadania e sustentabilidade. Cadernos de Pesquisa, n. 118, p. 189-205, mar. 2003. Disponível em: http://www.scielo.br/pdf/cp/n118/16834.pdf. Acesso em: 1o mar. 2018.

KENSKI, V. M. Educação e tecnologias: o novo ritmo da informação. Campinas, SP: Papirus, 2012.

LEFF, E. Saber ambiental. Sustentabilidade. Racionalidade. Complexidade. Poder. Petrópolis, RJ: Vozes; PNUMA, 2001.

LIMA, G. F. da C. Sustentabilidade e educação no século XXI: desafios e oportunidades na construção de uma democracia socioambiental. Coeb, 2013. Disponível em: http://portal.pmf.sc.gov.br/arquivos/arquivos/pdf/14_02_2013_16.36.30.7e628fbbf5c57b6393c6dd7ced076245.pdf. Acesso em: 10 mar. 2018.

LOUREIRO, C. F. B. Trajetória e fundamentos da educação ambiental. São Paulo: Cortez, 2000.

LUZZI, D. Educação ambiental: pedagogia, política e sociedade. In: PHILIPPI JUNIOR, A.; PELICIONI, M. C. F. Educação ambiental e sustentabilidade. Barueri, SP: Manole, 2014.

MADEIRA, L. M. Pesquisa participante: metodologia pedagógica alternativa para enfermeiros. Revista Brasileira de Enfermagem, Brasília, v. 40, n. 1, jan./fev./mar. 1987. Disponível em: http://www.scielo.br/ pdf/reben/v40n1/v40n1a05.pdf. Acesso em: 22 nov. 2018.

MARTINS, L. C. B. Implicações da organização da atividade didática com uso de tecnologias digitais na formação de conceitos em uma proposta de ensino híbrido. 2016, 317f. Tese (Doutorado) - USP, Programa de Pós-Graduação em Psicologia, Instituto de Psicologia da Universidade de São Paulo, 2016. Disponível em: http://www.teses.usp.br/teses/disponiveis/47/47131/tde-19092016-102157/pt-br.php. Acesso em: 22 nov. 2018.

MORAN, J. A educação que desejamos: novos desafios e como chegar lá. 5. ed. Campinas, SP: Papirus, 2012.

PELICIONI, A. F.; PHILIPPI JUNIOR, A. Bases políticas, conceituais, filosóficas e ideológicas da educação ambiental. In: PHILIPPI JUNIOR, A.; PELICIONI, M. C. F. Educação ambiental e sustentabilidade. Barueri, SP: Manole, 2014.

POLLI, A.; SIGNORINI, T. A inserção da educação ambiental na prática pedagógica. Ambiente \& Educação, v. 17, n. 2, 2012. Disponível em: https://periodicos.furg.br/ambeduc/article/view/2595. Acesso em: 10 jun. 2018.

RODRIGUES, N. Educação: da formação humana à construção do sujeito ético. Educação \& Sociedade, Campinas, v. 21, n. 76, p. 232-257, out. 2001. Disponível em: http://www.scielo.br/pdf/es/v22n76/ a13v2276.pdf. Acesso em: 15 fev. 2017.

SAVIANI, D. História das ideias pedagógicas no Brasil. Campinas, SP: Autores Associados, 2007.

SASSAKI, C. Quatro mitos sobre tecnologia e Educação que devem acabar em 2016. Blog Tecnologia na Educação. Nova Escola, 10 dez. 2016. Disponível em: http://novaescola.org.br/blogs/tecnologia-educacao/2016/01/12/quatro-mitos-sobre-tecnologia-e-educacao-que-devem-acabar-em-2016/. Acesso em: 9 jul. 2018.

SCHUNEMANN, D. R.; ROSA, M. B. da. Conscientização ambiental na educação infantil. Revista Monografias Ambientais, v. 1, n. 1, p. 122-132, nov. 2010. Disponível em: https://periodicos.ufsm.br/remoa/ article/view/2295. Acesso em: 10 mar. 2018.

SILVA, A. H.; FOSSÁ, M. I. T. Análise de conteúdo: exemplo de aplicação da técnica para análise de dados qualitativos. Qualitas Revista Eletrônica, v. 16, n. 1, maio 2015. Disponível em: http://revista.uepb.edu.br/ index.php/qualitas/article/view/2113. Acesso em: 10 mar. 2018.

STAKER, H.; HORN, M. B. Classifying K-12 blended learning. Mountain View, CA: Innosight Institute, Inc. 2012. Disponível em: https://www.christenseninstitute.org/wp-content/uploads/2013/04/Classifying-K-12-blended-learning.pdf. Acesso em: 10 mar. 2018.

TOZONI-REIS, M. F. de C. Pesquisa-ação em Educação Ambiental. Pesquisa em Educação Ambiental, v. 3, n. 1, p. 155-169, 2008. Disponível em: https://repositorio.unesp.br/bitstream/handle/11449/108279/ ISSN2177-580X-2008-3-1-155-169.pdf?sequence=1. Acesso em: 10 abr. 2018. 


\section{Rousta \\ \&Educaçẫo}

Suelen de Gaspi - Carlos Alberto de Oliveira Magalhães Júnior

VALENTE, J. A. Prefácio. In: BACICH, L.; TANZI NETO, A.; TREVISANI, F. de M. (org.). Ensino híbrido: personalização e tecnologia na educação. Porto Alegre: Penso, 2015.

VALENTE, J. A.; ALMEIDA, M. E. B.; GERALDINI, A. F. S. Metodologias ativas: das concepções às práticas em distintos níveis de ensino. Revista Diálogo Educacional, Curitiba, v. 17, n. 52, p. 455-478, abr./jun. 2017. Disponível em: https://periodicos.pucpr.br/index.php/dialogoeducacional/article/view/9900. Acesso em: 12 jun. 2018.

ZABALA, A. A prática educativa: como ensinar. Porto Alegre: ArtMed, 1998. 